\title{
Why Enterprise Modelling? An Explorative Study into Current Practice
}

\author{
Anne Persson ${ }^{1}$ and Janis Stirna ${ }^{2}$ \\ ${ }^{1}$ Department of Computer Science, University of Skövde, P.O. Box 408, SE-541 28 \\ Skövde, Sweden \\ anne.persson@ida.his.se \\ 2 Department of Computer and Systems Sciences, Royal Institute of Technology and \\ Stockholm University, Electrum 230, SE-16440, Kista, Sweden \\ js@dsv.su.se
}

\begin{abstract}
This paper presents an explorative study, which investigates the intentions behind current use of Enterprise Modelling (EM) in organisations. The intentions fall into two main categories: developing the business and ensuring the quality of the business. The results indicate that current methods are useful for these purposes.
\end{abstract}

\section{Introduction and Background}

Enterprise Modelling (EM) is an activity where an integrated and negotiated model describing different aspects of an enterprise is created. An Enterprise Model consists of a number of related "sub-models", each describing the enterprise from a particular perspective, e.g. processes, business rules, goals, actors and concepts/information/ data. Much research has been put into the development of Enterprise or Business Modelling methods, while the practice of using them has been more or less neglected by the research community.

EM method developers have suggested that their methods are applicable in a variety of contexts; e.g. BPR, strategic planning, enterprise integration and IS development. We investigate which intentions, in fact, are behind current use of EM in organisations. The paper is based on two qualitative studies using interviews, case studies, company observations, and literature studies. They were carried out in two separate research projects addressing EM tool support and ways of working (in particular the participative approach). The implications of the findings with regard to these two issues are further discussed by Persson and Stirna (2001).

\section{Why Enterprise Modelling?}

The goal hierarchy in Fig.1, resulting from analysing the interviews, shows the common objectives that organisations have for using EM. It contains two main branches. One deals with developing the business, e.g. developing business vision, strategies, redesigning business operations, developing the supporting information 
systems, etc. The other deals with ensuring the quality of the business, primarily focusing on two issues: 1) sharing the knowledge about the business, its vision, the way it operates and 2) ensuring the acceptance of business decisions through committing the stakeholders to the decisions made. In the following two sections, the two branches will be discussed in more detail.

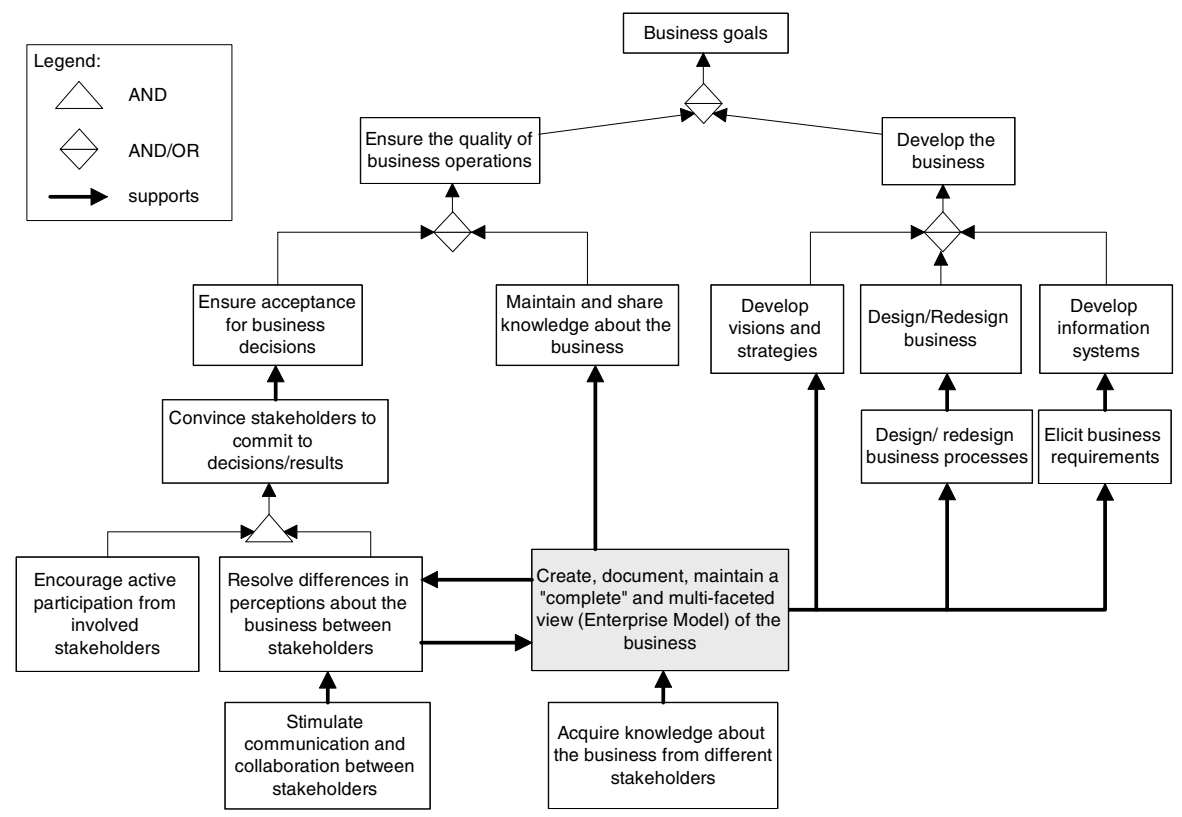

Fig. 1. Goal hierarchy of the most common intensions for using Enterprise Modelling

\section{Business Development}

Business development is one of the most common objectives for EM. It frequently involves change management - determining how to achieve visions and objectives from the current state in organisations. EM is used in this process with great success. Some specific issues addressed by EM are found in the following citation ${ }^{1}$ :

“... questions like strategies, what type of market to participate in, how is the market structured, which are our clients, who are the other interested parties in the organisation, how should we structure our work sequencing, how do we structure our products comparing with the clients, do we sell everything to everyone. EM also aims to describe the reason for the organisation, the goals - to relate them to the strategies, to the business idea. EM continues all the way from the strategies through the processes, through the concepts - in order to arrive at a complete picture, or a picture that fits together."

Business process orientation is a specific case of business development - the organisation wants to restructure/redesign its business operations.

\footnotetext{
${ }^{1}$ Note that the quotations from this point onwards are excerpts from the interviews. Full transcripts of the interviews are available from the authors on request.
} 
Also, EM is often used in the early stages of IS development. A common view is that EM can effectively be used for gathering business needs and high-level requirements. One experienced business consultant stated:

"In my experience, the most common modelling I have been doing, has been connected in some way to IT development. There has always been a superior decision of doing something in the IT sphere, which has led to the need to understand the business better and describe it much better, otherwise we can't build the right system. That is very often the situation. On the other hand I have not been very much involved in the rest of the IT development. I have just delivered the results - this is the business, this is how it's working, this is the information that needs to be handled. ... That's one situation. ...Another one is business process definition, where the idea as such has been to describe the business in terms of processes. Then other projects have sort of emerged. E.g. people see that some part of the business should be improved, or this part of the business is not supported by the IT at all."

\section{Quality Assurance}

Another common motivation to adopt EM is to ensure the quality of operations. Two important success factors for ensuring quality, mentioned by interviewees, were that stakeholders understand the business and they accept/are committed to business decisions. Recently, organisations have taken an increased interest in Knowledge Management, which is concerned with creating, maintaining and disseminating organisational knowledge between stakeholders. EM has a role to play here. Its aim is to create a multifaceted view of the business, which functions as a common platform for communicating between different stakeholders in the enterprise.

Sharing knowledge about the business becomes instrumental when two organisations merge or when different organisations collaborate in carrying out a business process. One part of the knowledge about a business is its terminology:

"I'm thinking about [organisation $X$ and organisation $Y$ ] where they realised that they could use the same data. To be able to do that, they must use the same terms so that they could buy from and sell to each other ... and then it was quite clear that they needed modelling of their business concepts."

One of the Knowledge Management perspectives is keeping employees informed with regard to how the business is carried out. For example:

“...in those days ... when the company was expanding enormously, they increased by about $100 \%$ personnel each year, and it grew very rapidly over the globe. ... So how should we introduce [new people] to the [company E] world and teach [them] how to handle all the things in the [company E] community, etc. It's simply not possible, especially since we don't have good documentation of how we really operate, because everything went on so quickly, that [company E] had to change routines almost every year because of the expansion, etc. So their main motive actually for describing their processes was not to get a lot more efficient, because, maybe rightly, they thought that they were rather efficient, but as a tool to communicate to newly hired personnel, and to show people - this is how we think we are operating, do you have any ideas"

If Enterprise Models are to play a role in the maintenance and dissemination of business knowledge there is a need for supporting tools.

Most modern organisations subscribe to the view that the commitment of stakeholders to carry out business decisions is instrumental for achieving high quality business operations. To this effect, differences in opinions must be resolved which, in turn, requires that communication between stakeholders be stimulated. EM, particularly using a participative approach, is effective to obtain commitment from stakeholders.

“... if you want people actively involved and if you want people to go along with what is decided, then they have to be allowed to be involved from the beginning and not get decisions forced on them from management.." 
"Active participation leads to commitment. So by achieving that, you make it impossible for people to escape commitment."

\section{Conclusion and Future Outlook}

We have discussed the role of EM in current practice and its perceived contributions to goals in an organisation. We show that EM in effect is used for a variety of purposes, such as creating visions and strategies, redesigning the business as well as for developing information systems. This seems to fit well with the intentions of EM method developers, which could indicate that available methods are in many ways useful. Apart from development purposes, EM seems also to play a role in ensuring the quality of the business. A recent challenge is the use of Enterprise Models in Knowledge Management. This challenge, among others, requires "mature" EM method and tool users.

In this paper we have focused on the true intentions behind the use of EM in organisations today. A further analysis of the implications of these findings on EM tool support and on ways of working has been carried out. This is discussed in detail in (Persson and Stirna, 2001). Some of the important conclusions from that analysis are:

- Participative EM is a strong way of truly committing stakeholders to business decisions, but should only be applied in consensus-oriented organisations.

- EM novices are poor judges of the applicability of participative EM. Nor can they assess which is the appropriate EM tool. Furthermore, they are not aware of their lack of knowledge in these respects, frequently causing EM projects to fail. These failures are often blamed on the methods and tools applied.

- Complex modelling tools tend to distract people from the issue at hand. In many cases, simple drawing tools can be just as effective if not more.

- EM activities require a modelling expert. Thus there is less need for method guidance facilities in tools. In fact, most modelling experts look for tools that provide as much freedom as possible.

- Tool vendors should play a more active role in getting to know what the practitioners need instead of overselling their products.

Current EM literature neglects the practical use of EM methods and related tools. It is important to bear in mind, however, that methods are only vehicles to take us somewhere. Modelling for the sake of modelling is not really useful. We have empirically found that method developers and researchers often forget this. The impression from our interviews is that practitioners feel the same way. More specifically, they feel that methods give very little guidance with regard to how and why methods and tools should be used in different situations.

\section{References}

Persson A., Stirna, J. (2001), "An explorative study into the influence of business goals on the practical use of Enterprise Modelling methods and tools", Technical report no HSIDA-TR-01-001, University of Skövde, Sweden. 